of a few weeks with no sequestrum whatsoever. At the very least a good opening must be made in the medulla. There is no sense in using a sharp spoon in the medulla-it does no good. What is necessary is a free opening for the evacuation of the pus. Bier's treatment is useless in this, as in all other conditions. Vaccines seldom have any effect. Antistreptococcic serum is of use in streptococcal cases. Plenty of fluid must be given-by mouth, per rectum, or subcutaneously ; this is absolutely essential.

Blood transfusions are occasionally necessary in desperate cases. One more point with regard to the operation. I do not consider that early total removal of the whole of a diaphysis is a sound procedure. It may be wise in chronic cases where there is a yood deal of new bone formation, but not as a primary operation in an acute case, unless the shaft is totally loose, but such a condition should never be allowed to occur. In removing sequestra in the chronic stages of the disease it is best to wait until these are loose, and then to leave a cavity of a shape that favours healing-i.e., one into which the soft tissues can fall with ease.

\section{ANTENATAL CARE AS IT AFFECTS THE CHILD IN UTERO.*}

\author{
BY \\ THOMAS WATTS EDEN, M.D. EDIN., \\ F.R.C.P. Lond., F.R.C.S. EdIN., \\ CONSULTING OBSTETRIC PHYSICIAN, CHARING CROSS \\ HOSPITAL, LONDON. \\ (Concluded from p. 39.)
}

\section{The Foetal Period.}

Effect of Maternal Diet.-A question related to that which we have just considered, but in reality distinct from it, is whether specific deficiencies in the mother's diet can influence the development of the fœtus. It is obvious that this may be so, although general insufficiency of food may be without effect. In its clinical aspect this question has hardly been explored at all, so far as I am able to find, but there is a certain amount of experimental work which I think deserves notice. In 1921 Reynolds and Macomber published a series of observations on the manner in which the fertility of rats could be influenced by feeding them on specifically deficient diets. In his experiments he took a certain strain of albino rats which had been inbred for 34 generations, and whose fertility-rate was well determined. The rate was somewhat lower than that of rats of a heterogenetic strain.

For the purpose of his experiments the rats were fed upon four different kinds of deficiency diet ; the deficient elements were not absent from the diet, but were present in quantity somewhat

* Post-graduate Lecture delivered at the Prince of IVales's General Hospital on July 19th, 1926. less than the standard quantities of the stock diet with which they are compared. The four varieties were :-

1. Low in fat-soluble vitamin.

2. Low in protein.

3. Low in calcium.

4. Double deficiency-i.e., low in protein and fat-soluble vitamins, high in carbohydrates.

The test consisted of determining the number of matings which proved fertile, and resulted in litters, under each form of diet, and the results were as follows :-

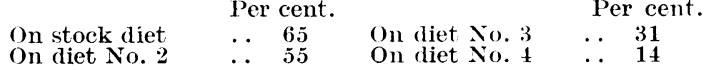

In addition to diminishing the number of fertile matings it was found that by continuing the deficiency diet through several generations complete infertility could be produced. These infertile rats were apparently well-developed animals, with the exception of those bred under a doubledeficiency diet, which were feeble and undersized.

The authors made a further very interesting observation-viz., that abortion with a macerated fotus occurred in eight instances out of a comparatively small number of rats on a doubledeficiency diet. After an extensive search through the literature of rat-breeding, they had failed to discover an instance of this occurrence under other conditions. The authors further state that Steinbock has also reported the birth of macerated fotuses in cattle and swine fed on similar deficiency diets.

It cannot be questioned that these observation. of Reynolds and Macomber are very suggestive. It is difficult to make tests of sufficient numbers of cases in clinical work, but occasional opportunities may arise of seeking the explanation of failure to conceive, or, after conception, of failure to carry the child to term, in deficiency of some important dietetic element. We have all seen those rare but puzzling cases in which a woman has on several occasions carried her child almost to term, and then for some quite obscure reason the fotus has died in utero before labour has set in. Such cases, of course, are generally syphilitic, but failing this explanation, it would be worth while to explore the possibility of a dietetic deficiency being the operative cause. Occasional instances of what used to be called "habitual abortion" may also possibly arise from some dietetic fault.

The calcium content of the diet of an expectant mother is especially deserving of consideration Blair Bell has estimated that the mother parts with $800 \mathrm{~g}$. of calcium during the nine months of pregnancy; unless this element is freely renewed in the diet, it is quite possible that the fotus may be calcium-starved with disastrous effects to it. vitality. Milk and green vegetables are the principal dietetic sources of calcium, and thi element can, of course, be readily supplemented medicinally.

Effects of Alcohol on the Foetus.-I do not wish to raise the vexed question as to whether 
or not alcohol is really a dietetic substance. There are, however, some considerations in regard to it which cannot be ignored in any review of the possible effects of maternal diet on the fotus. There is a very ancient belief that children begotten during drunkenness are liable to be deformed. This belief found its expression in pagan mythology, for Vulcan, the deformed son of Jupiter and Juno, was begotten when both parents were intoxicated; his deformed condition so angered his mother that she cast him into the volcano, where he laboured for ever at the forges of the gods. The tradition has survived, and, unlike the great majority of such myths, it appears to have a very good chance of being eventually established as a scientific fact. Already, in the opinion of several authorities, the point has been proved as nearly as such a point ever can be proved by clinical observation.

In considering the effects of alcohol, the first point to bear in mind is its great diffusibility. It becomes rapidly absorbed directly from the stomach and soon becomes equally diffused throughout the fluid and solid tissues of the body. It passes readily through the placenta and can be detected in the umbilical blood. Further, though readily diffusible, alcohol is not quickly eliminated; strictly speaking, it is not eliminated at all, but gradually destroyed by oxidation in the tissues of the body. Mellanby showed that after only a small dose of alcohol had been drunk it could be detected in the blood for 19 hours. I do not think it can be disputed that alcohol drunk by the mother will pass into the fotal circulation, that it will be present at any given moment in approximately the same degree of concentration in both mother and child, and that the child will be subjected to its influence for a comparatively long time, owing to the tardiness of its disappearance from the tissues. I cannot discuss the question whether the fotus will suffer any ill-effects; we should, however, recognise the fact that alcohol drunk by the mother will reach the fotus.

A good deal of experimental work has been done in recent years to determine the effect upon their offspring of subjecting animals, both male and female, before mating, to the effects of the fumes of alcohol, continued for a long period. Stockard has carried out a series of experiments with guineapigs which have been continued for 12 years, and cover many generations of animals. His method was to expose the guinea-pigs to a daily inhalation of alcohol fumes up to the point of intoxication. He found that very marked results were observed in the young of the alcoholised animals. He found, in brief : (1) that the fertility of the animals was diminished; (2) that the young were deficient in vigour and in power of survival after birth; (3) that a high proportion of developmental defects occurred; (4) that these defects were practically confined to the central nervous system and the organs of special sense; and (5) the defects were transmitted, in some instances, to the third generation, although only the original grandparents $\stackrel{\text { की }}{0}$ had been subjected to the influence of alcohol.

That alcoholism in the parents is one of the most important predisposing causes of mental deficiency (amentia) and epilepsy all the authorities on this ${ }^{\circ}$ subject are agreed. We have no precise observations as to the difference, if any, between the children of alcoholic and non-alcoholic parents aso regards birth-weight and general vitality. The information we do possess, however, is, I think, sufficient to lay upon us the duty of advising $\stackrel{\odot}{\circ}$ abstinence from alcohol during pregnancy, and of $\stackrel{2}{q}$ pointing out clearly the possible deleterious effects ${ }^{\infty}$ on the child of over-indulgence.

Effects of Maternal Disease.-When we come $\overrightarrow{\vec{H}}$ to consider the case of the fotus in utero ${ }^{\omega}$ which is subjected to the influence of maternato disease, a field is opened up which is so 3 . wide that it will only be possible to glance atị the subject. There are no national statistics of $\vec{\sigma}$ the causes of antenatal death, and such informationcy as we can gather about it is gleaned from the veryo valuable reports which most of our lying-in hospitals now publish. There are also some $_{\vec{C}}$ foreign statistics of which we can make use.

Couvelaire has recently published data taken from the records of the Clinique Baudelocque in Paris, over a series of 20 years -1890 to $1919 \vec{\circ}$ inclusive. During this period out of 57,642 births, there were 1769 cases in which the fœtus hado perished before the onset of labour, equivalent too a stillbirth-rate of 3.0 per 100 births. It appears, further, that in this series more than 50 per cent. of the fotal mortality could be traced to syphilis and to pregnancy toxæmias taken together. The only English data that we have bearing on theo frequency of syphilis in the fotus are those furnished ${ }_{5}^{3}$ by Eardley Holland in his recent work on the Causation of Fœtal Death, carried out under the:auspices of the Ministry of Health. In his examina-o tion of 300 dead-born foetuses, only 42 cases of "proven" and six of "probable" syphilis were 3 found, making together - i.e., including the "probables" - 16 per cent. of the whole as due to syphilis. These figures are not really comparable to Couvelaire's, because in the latter the diagnosis? was established not only by examination of the fotus and placenta, but also by clinical examination?. of the parents, including the Wassermann reaction $N$ Even when allowance is made for these divergences $N$ it would appear that in the practice of lying-in hospitals syphilis is less common in London than in Paris. Probably a large proportion of ouk syphilitic mothers go to the Poor-law infirmary fore their confinement rather than the lying-in hospitals At the same time it may be pointed out that our lying-in hospitals, and especially the antenata유 clinics, have the opportunity of rendering a great public service by instituting a strict search for latent syphilis in women with a bad obstetrio history. Modern methods of antisyphilitic treato ment have in no department achieved more striking successes than in the prevention and cure 
of congenital syphilis. If all syphilitic mothers could be adequately treated during pregnancy, the congenital syphilitic child would disappear, and the part which obstetricians could play in this work is clearly a most important one, for even if the hospitals have not facilities for treatment, they could make the diagnosis and see that the patient was treated elsewhere. Couvelaire has published his results of antisyphilitic treatment at the Clinique Baudelocque during the years 1920-22. In 256 cases treatment was applied to the mothers as follows :--

1. Only during the later months: these women had a fœtal mortality of 30 per cent.

2. Throughout pregnancy : these had a fœtal mortality of 15 per cent.

3. Before and during pregnancy: these had a fœtal mortality of 3 per cent.

In contrast there were 218 untreated cases of recent syphilis which gave a fœtal mortality of from 65 per cent. to 70 per cent.

Results almost as striking as these have been obtained in London by John Adams at the V.D. Clinic for Syphilitic Mothers, established under the auspices of the Metropolitan Asylums Board.

\section{Intranatal Period.}

Intranatal risks-i.e., those which occur during the process of birth, are still awaiting the fœtus which survive the risks incidental to pregnancy.

Intranatal death is in the main attributable to what we may call, using the term in a broad sense, birth-traumatism. Birthtraumatism is also responsible for a considerable number of neonatal deaths, the injury received in the birth process not being immediately fatal.

It is a little difficult to form any clear idea as to what are the fotal risks incidental to the birth processes alone, because in order to determine this it is necessary to eliminate maternal complications, such as ante-partum hæmorrhage and eclampsia, which tend of themselves to imperil the life of the child. Table I. represents an attempt to do this which $I$ am afraid is not as successful as I had at one time hoped to make it. The gross rate, $A$, including all cases of dead-born children ; then a corrected rate, which we may call $B$, obtained after deducting all cases returned as macerated : then a third rate, $\mathrm{C}$, which has been obtained by deducting cases of craniotomy, of ante-partum hæmorrhage, and of eclampsia from rate $B$ (vide infra). The addition to rate $C$ of neonatal deaths, directly traceable to injury, will give us the true intranatal death-rate. It will be recollected that the stillbirth-rate for the whole country is $3 \cdot 3$ per cent., and the dimensions of rate $A$, in most of the hospitals, is unexpectedly high. The rate is not much reduced by the exclusion of macerated fœtuses, except in the case of one hospital, and it will be seen that rate $B$ is, on the average, less than 10 per cent. below rate $A$. The exclusion of the various maternal complications, however, cuts rate $B$ down to little more than one-half in the case of all the hospitals alike. The figures shown in the table $\frac{0}{0}$ have been calculated for an average of five vears ڤ in all but No. 6, for which only three years were $\frac{2}{3}$ available.

TABLE I.-Fotal Death-rate in Six Lying-in Hospitals.

\begin{tabular}{|c|c|c|c|c|c|c|c|}
\hline \multirow{2}{*}{$\begin{array}{r}\begin{array}{r}\text { Hospital: } \\
\text { 5 years' } \\
\text { average. }\end{array} \\
\\
1 \\
2 \\
3\end{array}$} & \multirow{2}{*}{$\begin{array}{c}\begin{array}{c}\text { Gross } \\
\text { rate. }\end{array} \\
\mathbf{A .} \\
\begin{array}{c}\% \\
15 \cdot 7 \\
12 \cdot 2 \\
12 \cdot 9\end{array}\end{array}$} & \multicolumn{2}{|c|}{$\begin{array}{l}\text { Corrected } \\
\text { rate. }\end{array}$} & \multirow{2}{*}{$\begin{array}{r}\begin{array}{r}\text { Hospital : } \\
\text { 5 years' } \\
\text { average. }\end{array} \\
\\
4 \\
5 \\
6\end{array}$} & \multirow{2}{*}{$\begin{array}{c}\begin{array}{c}\text { Gross } \\
\text { rate. }\end{array} \\
\mathbf{A .} \\
\% \\
\mathbf{1 2 \cdot 0} \\
\mathbf{5 . 9} \\
\mathbf{5 . 3 8}\end{array}$} & \multicolumn{2}{|c|}{$\begin{array}{c}\text { Corrected } \\
\text { rate. }\end{array}$} \\
\hline & & $\begin{array}{c}\text { B. } \\
\% \% \\
14 \cdot 7 \\
11 \cdot 5 \\
11 \cdot 7\end{array}$ & $\begin{array}{c}\text { C. } \\
\% \\
8 \cdot 9 \\
5 \cdot 7 \\
5 \cdot 6\end{array}$ & & & $\begin{array}{r}\text { B. } \\
\% \\
\mathbf{9 . 9} \\
\mathbf{5 . 4} \\
\end{array}$ & $\begin{array}{l}\text { C. } \\
\% \\
\mathbf{5} \cdot \mathbf{3} \\
\mathbf{3} \cdot \mathbf{1}\end{array}$ \\
\hline
\end{tabular}

The difference between the fotal mortality- $\frac{\vec{\omega}}{\omega}$ rate of the first and last hospitals on the list is $\stackrel{\mathrm{W}}{\mathrm{D}}$ surprising. Hospitals 1 to 4 are all situated in 8 great industrial centres : Nos. 5 and 6 are in London 3 . and their patients are drawn from a class which is i engaged almost entirely in domestic work and $\vec{\sigma}$ business, or light factory occupations. There are of no heavy industries in the parts of London served 0 by these hospitals. The rate A figures for hospitals 2,3 , and 4 are so nearly identical that they carry conviction of their reliability, and I think we may take it that they indicate that the loss of fœtal life is considerably higher in an industrial population than in what, for contrast, we may call a $\overrightarrow{0}$ non-industrial population. We cannot enter into $\mathrm{N}$ any consideration of what these causes may be, but the point is deserving of further inquiry.

One or two points may be cleared up by looking into the recorded causes of death in Group C. They fall into three main groups: (1) birthtraumatism, (2) prematurity, and (3) congenital defects and diseases.

Not all the hospitals furnish information sufficiently detailed for our purpose, but I have been able to examine an aggregate of 561 stillbirths falling into rate $\mathrm{C}$, with the result shown as follows :-

Of 561 still-births falling under rate $\mathrm{C}-$

48.7 per cent. were due to trauma.

8.3 per cent. were due to prematurity.

4.9 per cent. were due to defects and diseases.

The remainder, amounting to a little more than $\frac{9}{5}$ one-third, were unexplained, or due to a variety $\rightarrow$ of conditions which do not lend themselves to classification.

It appears, then, that if we exclude cases in which labour was complicated by serious maternal 0 complications, nearly half the fotal mortality in $\omega$ the lying-in hospitals whose reports were examined $\widetilde{F}$ is due to birth-traumatism. Of course, not all o the cases included under this heading showed $\mathbb{D}$ recognisable signs of injury ; in a small proportion + death was returned as due to "stress of labour" 꿍 or some equivalent term. There is no doubt $\frac{O}{\mathbb{D}}$

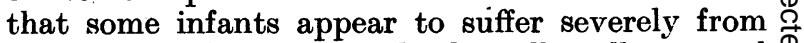
the effects of what we should clinically call a normal $\stackrel{\AA}{\AA}$ labour; the transit of the child through the maternal passages will no doubt always carry with it risks the extent of which depends in part upon 
that incalculable factor, the endurance of the child.

A large number of deaths from traumatism occurred in premature children whose power of resistance to shock is very low in comparison with the mature child. The two causes of injury and prematurity are closely related, and it will be interesting to look a little more closely into the question of premature births.

The accompanying table brings out two or three points which are of some importance. The second column gives the proportion of births

TABLE II.-Premature Births.

\begin{tabular}{|c|c|c|c|c|c|}
\hline \multirow{2}{*}{ Hospital. } & \multirow{2}{*}{$\begin{array}{l}\text { Pre- } \\
\text { mature } \\
\text { birth- } \\
\text { rate. }\end{array}$} & \multicolumn{2}{|c|}{ Stillbirth-rate. } & \multicolumn{2}{|c|}{ Neonatal death-rate. } \\
\hline & & $\begin{array}{c}\text { Pre- } \\
\text { mature. }\end{array}$ & Mature. & $\begin{array}{c}\text { Pre- } \\
\text { mature. }\end{array}$ & Mature. \\
\hline $\begin{array}{l}3 \\
5 \\
6\end{array}$ & $\begin{array}{c}0 \% \\
32 \% 9 \\
10 \cdot 76 \\
12 \cdot 24\end{array}$ & $\begin{array}{r}\% \\
21 \cdot 21 \\
25 \cdot 29 \\
20 \cdot 80\end{array}$ & $\begin{array}{c}\% \\
\% \\
4 \cdot 30 \\
3 \cdot 66 \\
3 \cdot 17\end{array}$ & $\begin{array}{c}\% \\
15 \cdot 29 \\
17 \cdot 46 \\
13 \cdot 50\end{array}$ & $\begin{array}{c}\% \\
\% \\
1 \cdot 10 \\
3 \cdot 47 \\
0 \cdot 55\end{array}$ \\
\hline
\end{tabular}

which were premature in three different hospitals. In hospital 3 nearly one-third of the children born in the hospital were premature; this hospital, as I have said, serves a large industrial centre. In the case of hospitals 5 and 6 , the proportion is 10 per cent. and 12 per cent. respectively. All the hospitals serving industrial districts show about the same premature birth-rate as hospital 3 . This table certainly suggests that women engaged in industrial work are unable to carry their children to term in anything like the same proportion as those engaged in lighter occupations. You will recollect that a somewhat similar observation was made by Pinard many years ago in Paris. It is impossible to pursue this point any further, but it also appears to be deserving of more extended inquiry.

Column 3 of this table shows the comparison between the proportion of premature and mature babies which are still-born, and it is not surprising to find that the premature stillbirth-rate is from five to seven times higher than the stillbirth-rate for mature babies. This is partly accounted for by the fact that the greater number of fœtuses born macerated are premature ; from the hospital reports I should judge the proportion to be about 60 per cent. The most important factors, however, are that maternal complications are more frequent in premature labour, and that even in their absence, the premature foetus is less able to endure the stress of labour than is the mature one.

Column 4 compares the chances of survival after birth of premature and mature babies under the same hospital conditions. Here the comparison is enormously to the disadvantage of the premature baby. The neonatal death-rate of the prematures does not vary greatly in the three hospitals, and may be put at 15 per cent. The death-rate of the mature infants varies widely from one-fifth to one-twelfth of the premature rate. The figure of 3.47 for hospital $\tilde{j}$ was due to exceptional circumstances which prevailed during two of the five years under review, and does not truly represent the average for that hospital. But between hospital 3 and hospital 6 there is a difference of 100 per cent. in favour of the latter.

There is, as we have seen, some evidence that social and industrial conditions may also be concerned in the causation of premature births, and this evidence may be shortly summarised thus :-

(a) Pinard showed that women admitted to hospital during the latter part of pregnancy carried क to term in larger proportion than those who $\overrightarrow{0}$ continued at work.

(b) Darwall Smith showed that premature births $\vec{\omega}$ were four times as frequent in women with bad nutritional conditions as in those of average $\frac{0}{3}$ nutritional conditions.

(c) The English lying-in hospitals serving industrial districts with a large factory population of show a proportion of premature births three times $y$ as high as London hospitals serving districts with 응 a relatively small factory population

\section{POST-GRADUATE WORK IN ${ }^{\frac{D}{2}}$ VIENNA.

WITH A NOTE ON POST-GRADUATE WORK IN BERLIN.

BY

J. L. MEAGHER, M.B., B.S. Melb., L.M. Coomre. (Concluded from p. 4\%.)

\section{Centralisation of Work.}

THF work was aided very much by the central situation of the chief hospitals. The largest, the general hospital, resembling in its drab colour and $\frac{3}{3}$ sprawling disposition a barrack, occupies a huge ${ }_{\bar{\sigma}}$. block near the centre of the city. It comprises 3 . the chief medical and surgical clinics. Other, $\delta$ more modern, magnificently appointed clinics are in the immediate neighbourhood. The greatesto distance between the chief city clinics is less than half a mile. The existence of the medical bookshops and instrument shops in the quarter increases the facilities for the post-graduate.

Another feature of interest in post-graduate N studies is the great German medical literature, ్ㅐ periodical as well as text-book (not all of it, however, $\sigma$ of unquestionable value), and the excellence of the printing, binding, and colour processes of standard works.

Organisation of Courses.

The task of picking up knowledge would be, for the average graduate from one of the Fnglishspeaking countries, impossible if it were not for $\frac{\vec{\Phi}}{\mathbb{Q}}$ the existence of the American Medical Association. It has commercialised, and to an extent degraded, the teaching. Teachers have tended, under theo 